Copyright ( $) 2020$ University of Bucharest

Printed in Romania. All rights reserved

ISSN print: $1224-5984$

ISSN online: $2248-3942$
Rom Biotechnol Lett. 2020; 25(3): 1563-1571 doi: $10.25083 / \mathrm{rbl} / 25.3 / 1563.1571$

Received for publication, August, 2, 2018

Accepted, October, 30, 2018

Original paper

\title{
The management of strong opioid-induced constipation in neoplastic patients
}

ROXANA-ANDREEA RAHNEA-NIŢĂ ${ }^{1}$, CRISTINEL DUMITRU BADIU ${ }^{2,3}$, ANDA NATALIA CIUHU ${ }^{4}$, MIHAELA MANDU ${ }^{2}$, LILIANA FLORINA ANDRONACHE ${ }^{3}$, VALENTIN TITUS GRIGOREAN ${ }^{2,3}$, TIBERIU SPIRCU ${ }^{3}$, ADRIAN PAUL SUCEVEANU ${ }^{5}$, FLORENTINA GHERGHICEANU ${ }^{3}$, CORNELIA NITIPIR ${ }^{3}$, CATALIN GABRIEL SMARANDACHE ${ }^{3,6}$, GABRIELA RAHNEA-NIŢÄ $\breve{3}^{3,4}$

1"Dr. Constantin Gorgos" Titan Psychiatric Hospital, Department of Oncology, Bucharest, Romania

2"Bagdasar-Arseni” Clinical Emergency Hospital, Department of General Surgery, Bucharest, Romania

3"Carol Davila" University of Medicine and Pharmacy, Bucharest, Romania

4"Saint Luca” Chronic Disease Hospital, Department of Chronic Oncology - Palliative Care, Bucharest, Romania

5"Ovidius" University, Faculty of Medicine, Emergency Hospital of Constanta, Constanta, Romania

6“Emergency University” Hospital, IV Departnet of Surgery, Bucharest, Romania

\begin{abstract}
Patients who undergo intensive treatments with high doses of opiates will be confronted with opiate-induced constipation at a certain point during the treatment. This aspect, the presence of medication-induced constipation, significantly alters the quality of life in a negative way. From the very beginning of the opioid treatment initiation, patients should be warned about and they should become aware of the potential adverse effects of these medications, since constipation has a strong psychological impact. As a palliative treatment, laxatives should be administered from the first day of the opioid treatment.
\end{abstract}

Keywords Cancer pain, strong opiates, constipation.

To cite this article: RAHNEA-NIŢ̆ R-A, BADIU CD, CIUHU AN, MANDU M, ANDRONACHE LF, GRIGOREAN VT, SPIRCU T, SUCEVEANU AP, GHERGHICEANU F, NITIPIR C, SMARANDACHE CG, RAHNEA-NIŢĂ G. The management of strong opioidinduced constipation in neoplastic patients. Rom Biotechnol Lett. 2020; 25(3): 1563-1571. DOI: $10.25083 / \mathrm{rbl} / 25.3 / 1563.1571$

$\triangle$ *Corresponding author: S CRISTINEL DUMITRU BADIU, M.D., Ph.D., "Carol Davila” University of Medicine and Pharmacy, Bucharest, Romania

E-mail: doctorcristianbadiu@yahoo.com 


\section{Introduction}

Whether it is a somatic, a visceral or a neuropathic pain syndrome, it is highly prevalent among cancer patients LI \& al [1]. Studies show that approximately $90 \%$ of the patients diagnosed with this pathology develop episodes of pain at a certain point in the evolution of the disease, most of whom require strong $3^{\text {rd }}$ degree analgesia, and also strong opioid treatment TRESCOT [2]. However, despite their efficiency as an analgesic therapy, opioids determine a series of adverse reactions, such as gastrointestinal. Constipation is the most common of all DORN \& al [3].

The occurrence of opioid-induced constipation can be physio-pathologically explained through the fact that these substances impair the normal functions at the level of the digestive tract, primarily by inhibiting peristalsis and gastrointestinal motility, secondly, by the tonic spastic action at the level of the intestinal and colon muscles, and thirdly by inhibiting the electrolyte secretion by favoring water retention, and last but not least, by the dysfunction they cause in the anal sphincter, action which contributes to the clinical picture manifested through the sensation of anal blockage and incomplete defecation HOLZER [4], KUMAR \& al [5], KURZ \& al [ 6].

By making a cause-effect connection between the two above-mentioned ideas, it could be stated that most of the patients confront themselves with opioid-induced constipation at a certain point. It represents a major problem among neoplastic patients, because it significantly alters the quality of life in a negative way BELL \& al [7]. Moreover, there are studies which have monitored paindetermined stress and constipation-determined stress, which concluded that pain is less stressful for the patient compared with the constipation induced during the treatment for pain HOLMEZ [8], RUMMAN \& al [9] TIGLIS \& al [10]. This sometimes determines the patient not to be compliant with the analgesic treatment, to interrupt it, thus entering the vicious circle in which he feels pain without opioids or he has constipation with opioids BALMUS \& al [11] DOBRICA \& al [12]. The main question that arises on this subject refers to the correct management of strong opioid-induced constipation.

\section{Material and Methods}

A group of patients undergoing treatment with strong opioids was admitted to the Chronic Oncology-Palliative Care Unit of "Saint Luca" Hospital in Bucharest.

A number of 160 patients was assessed and then a strong opioid treatment for severe pain was initiated. Out of these, 70 patients had also breakthrough pain, which required the administration of two opioids.

These patients were admitted into the department between January $1^{\text {st }}$ and July 1st, 2017. They signed the informed consent. The study was approved by the ethical board of "Saint Luca" Hospital. The data were analyzed in SPPS.

\section{Results}

The minimum age of the group was 29 years, the maximum - 87 years, the average $( \pm \mathrm{sd}) 62.5( \pm 10.5)$ years. The age and the gender distribution can be seen in Figure 1 .

The classification by types of cancer showed that more than $73 \%$ of the patients had lung cancer, as seen in Figure 2.

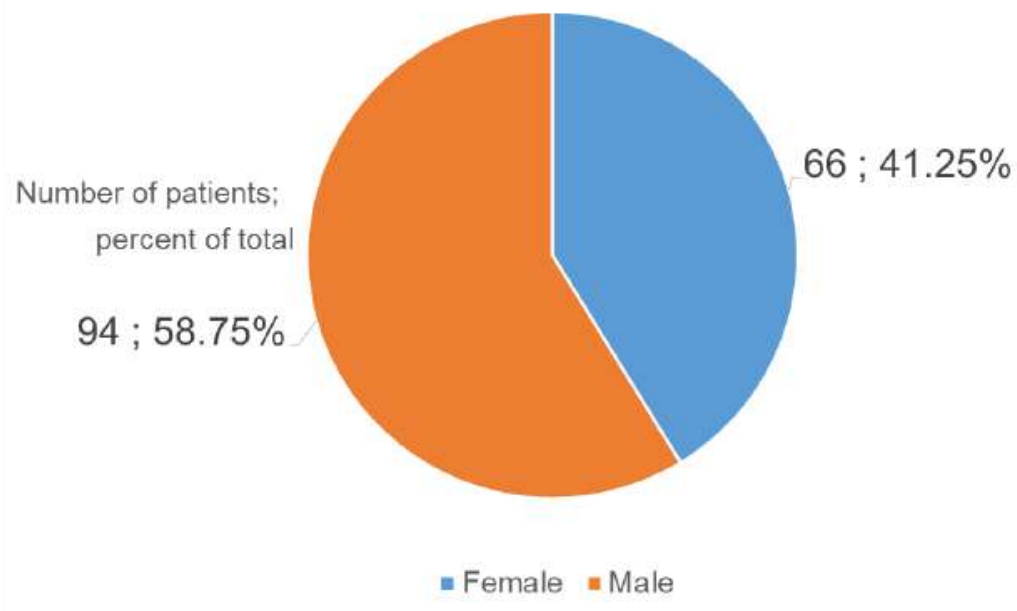

Figure 1. Distribution groups by gender 


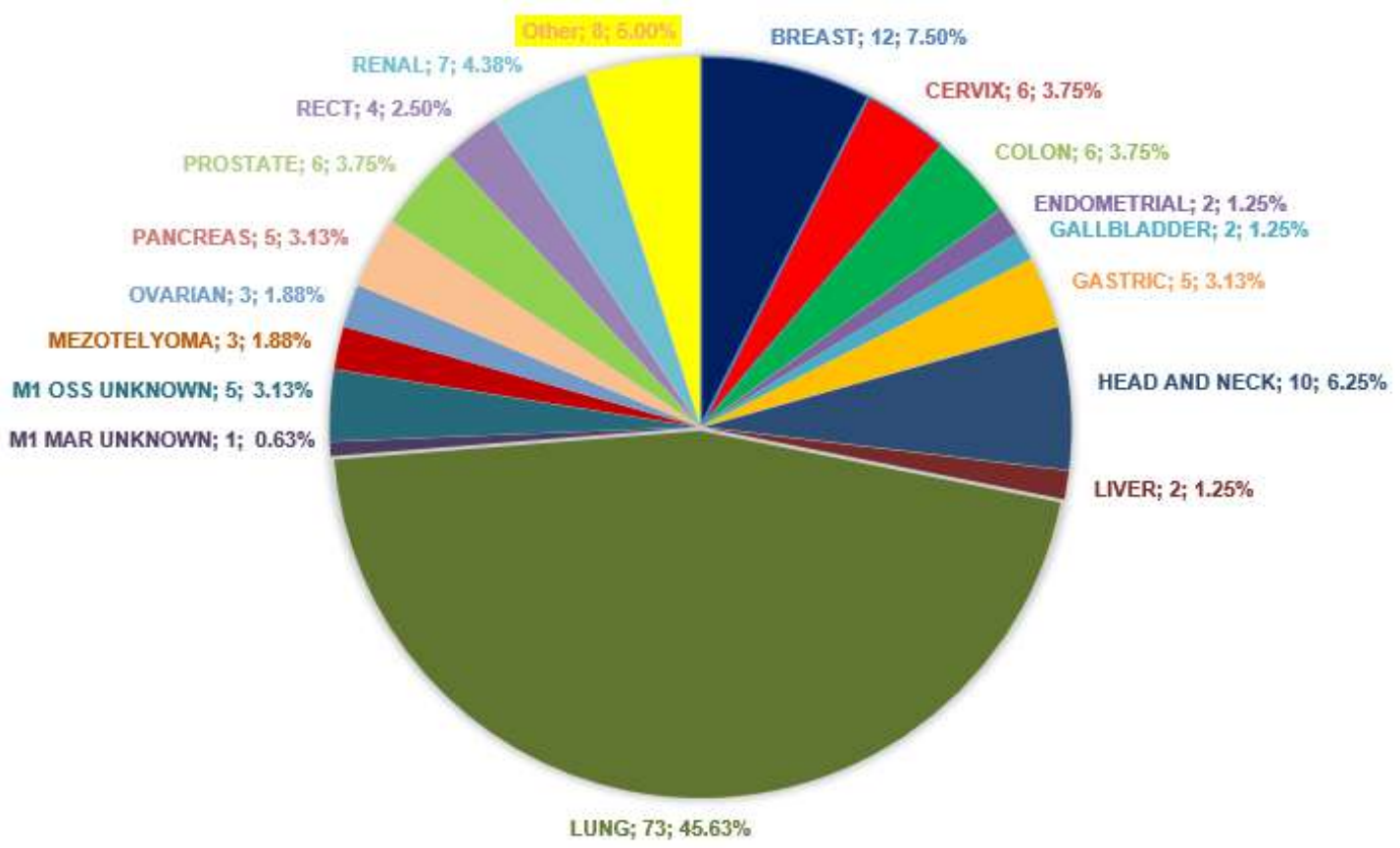

Figure 2. Distribution of types of cancer.

Following the application of the ECOG Scale of Performance Status questionnaire, which evaluated the impact of the disease on the quality of life of the neoplastic patient, $63.75 \%$ of the patients had a score of 3 indicating a limitation of normal daily activity and limited self-care capacity. On the other hand, as seen in Figure 3, 28.13\% of the patients were assessed with score 4, this being the most severe degree if we do not take into account the death score of 5 .

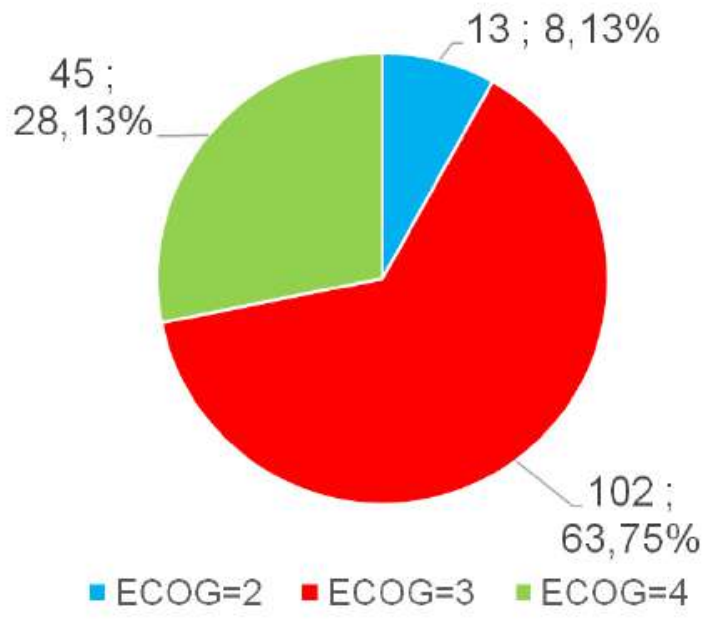

Figure 3. ECOG performance status score distribution

Strong opioids used for the treatment of chronic severe pain were: morphine, fentanyl patch and slowrelease tablets (oxycodone, morphine sulphate, morphine hydrochloride), morphine or immediate-release tablets (morphine sulphate or fentanyl) were added for breakthrough pain (BTP).

The prevention of constipation was done through the association of a laxative treatment and physical measures (diet, hydration and ambulation) from the first day of major opioid treatment initiation. 
The intensity of constipation was evaluated, according to The Edmonton Symptom Assessment System (ESAS) (other symptoms - constipation). ESAS is a screening tool in the oncology department of "Saint Luca" Hospital. One week after treatment initiation and also 3 weeks after treatment initiation, the score given was: $0=$ without constipation, $1-3=$ low-intensity constipation, 4-6=moderate-intensity constipation, 7-10=high-intensity constipation BRUERA \& al [13].

The laxative used at the beginning of the treatment was lactulose, in a dose of 10-20 $\mathrm{g}$ (15-30 ml/day).
The patients who presented high and moderate-intensity constipation one week after the initiation of the treatment were also given bisacodyl 5-10 mg/day.

The patients who were constant in high-intensity constipation under two laxatives were also given microenemas so that they could defecate every 4 days at most.

As for the treatment of chronic high-intensity pain, 90 patients underwent treatment with one major opioid, while 70 patients also received a second major opioid for the treatment of breakthrough pain, as seen in Figure 4.

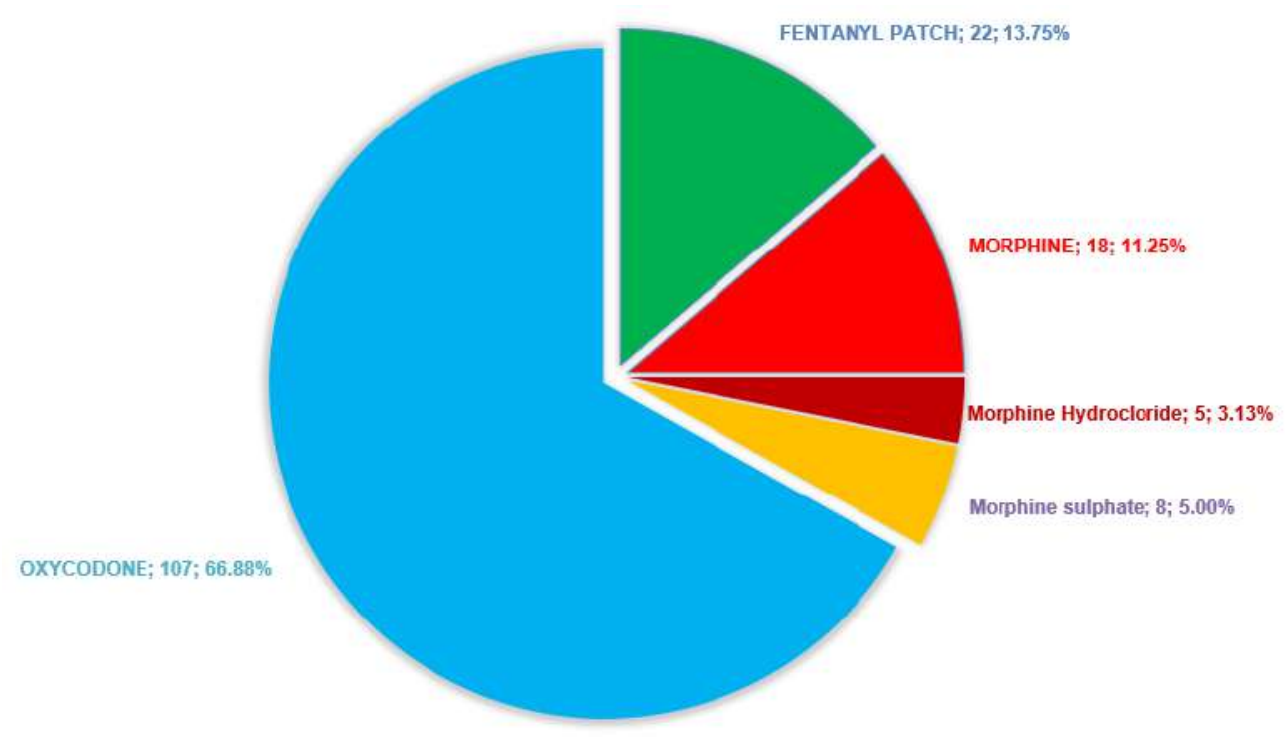

Figure 4. Distribution of patients after morphine or opioids taken for chronic pain.

The doses of major opioids used in the treatment of chronic pain were: morphine (20 mg - $120 \mathrm{mg} /$ day), fentanyl patch (25 micrograms - 150 micrograms every $72 \mathrm{~h}$ ), oxycodone (40 mg - $200 \mathrm{mg} /$ day), slow-release morphine sulphate $(60 \mathrm{mg}-180 \mathrm{mg} /$ day $)$, morphine hydrochloride (60 mg - $300 \mathrm{mg} /$ day) (Figure 5).
The doses of major opioids for breakthrough pain (BTP) were: morphine (20 mg - $40 \mathrm{mg} /$ day), fentanylimmediate-release tablets (300-900 micrograms/day), immediate-release morphine sulphate (20-80 mg/day), see Figure 6.

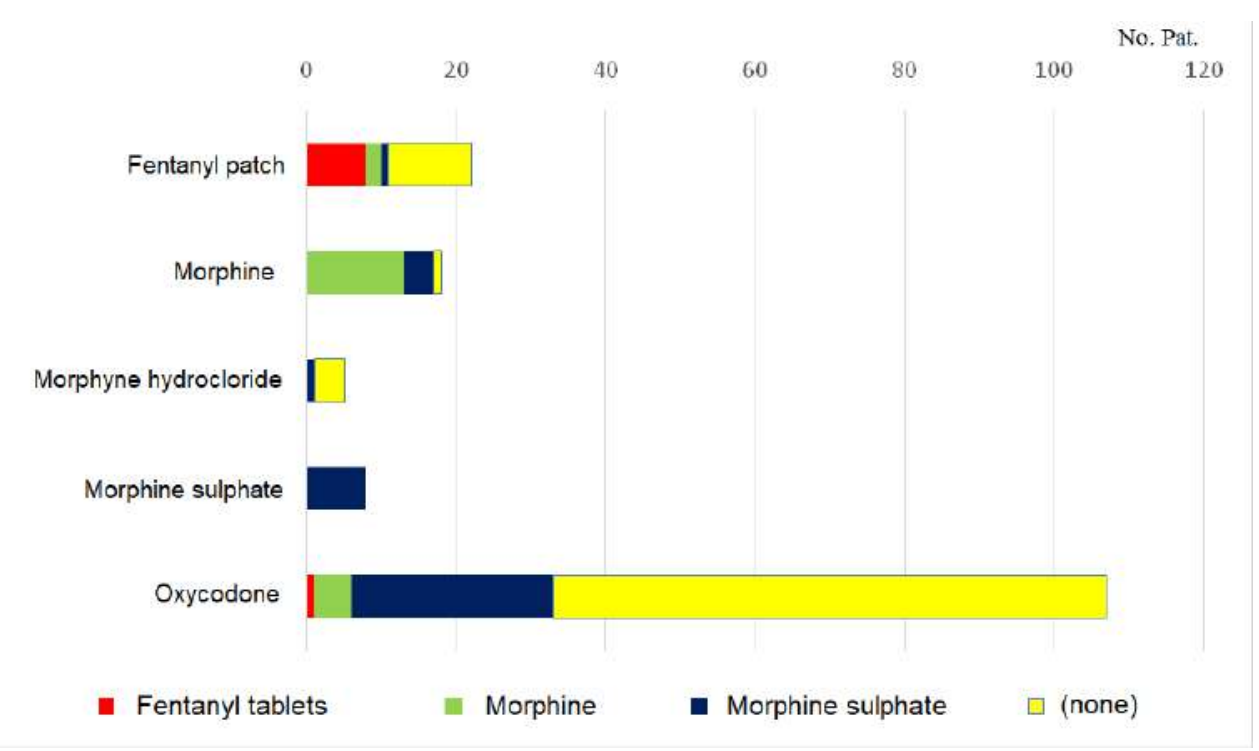

Figure 5. The doses of major opioids used in the treatment of chronic pain. 


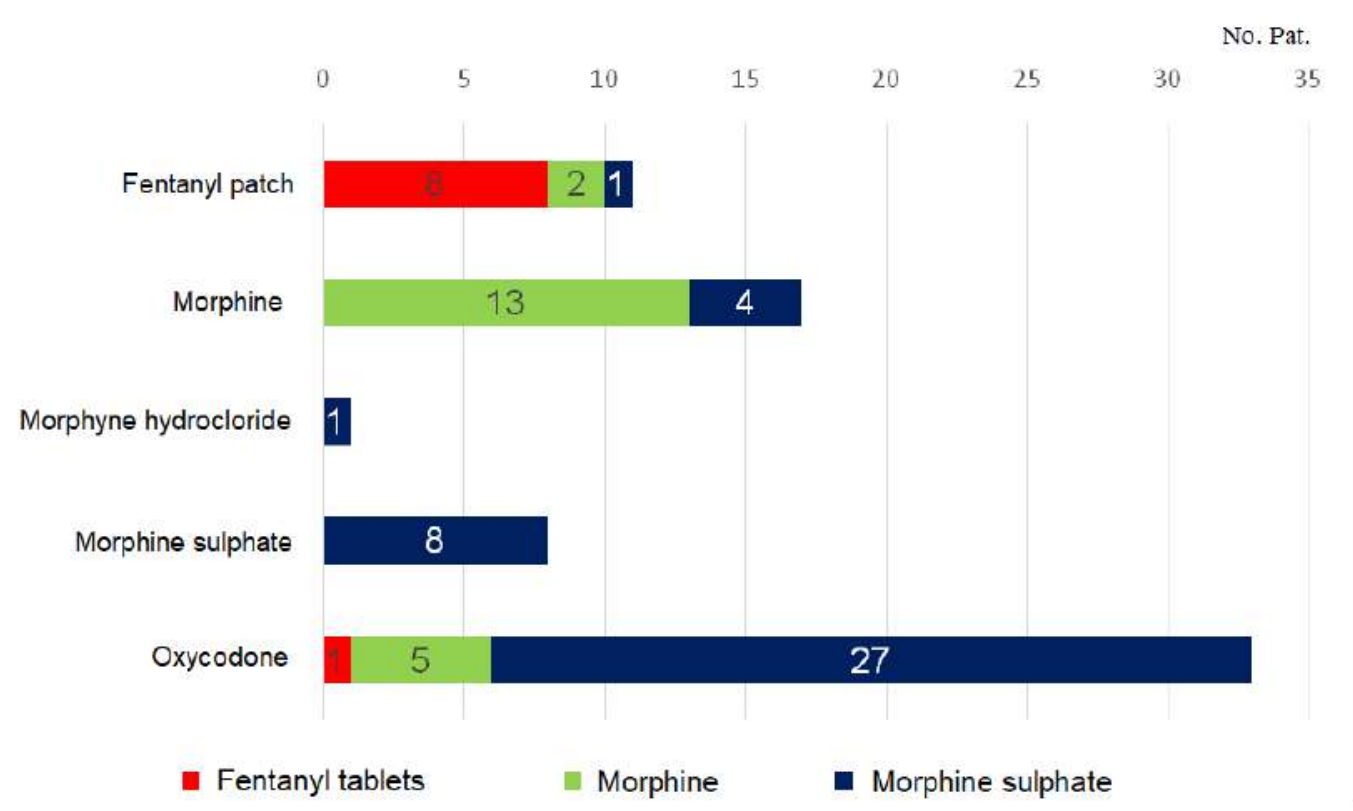

Figure 6. The doses of major opioids for breakthrough pain (BTP).

One week after treatment initiation with lactulose, the distribution of patients according to the intensity of constipation was: severe -32 patients, moderate -
49 patients, low - 55 patients, while 24 patients were not constipated at all. (Figures 7,8)

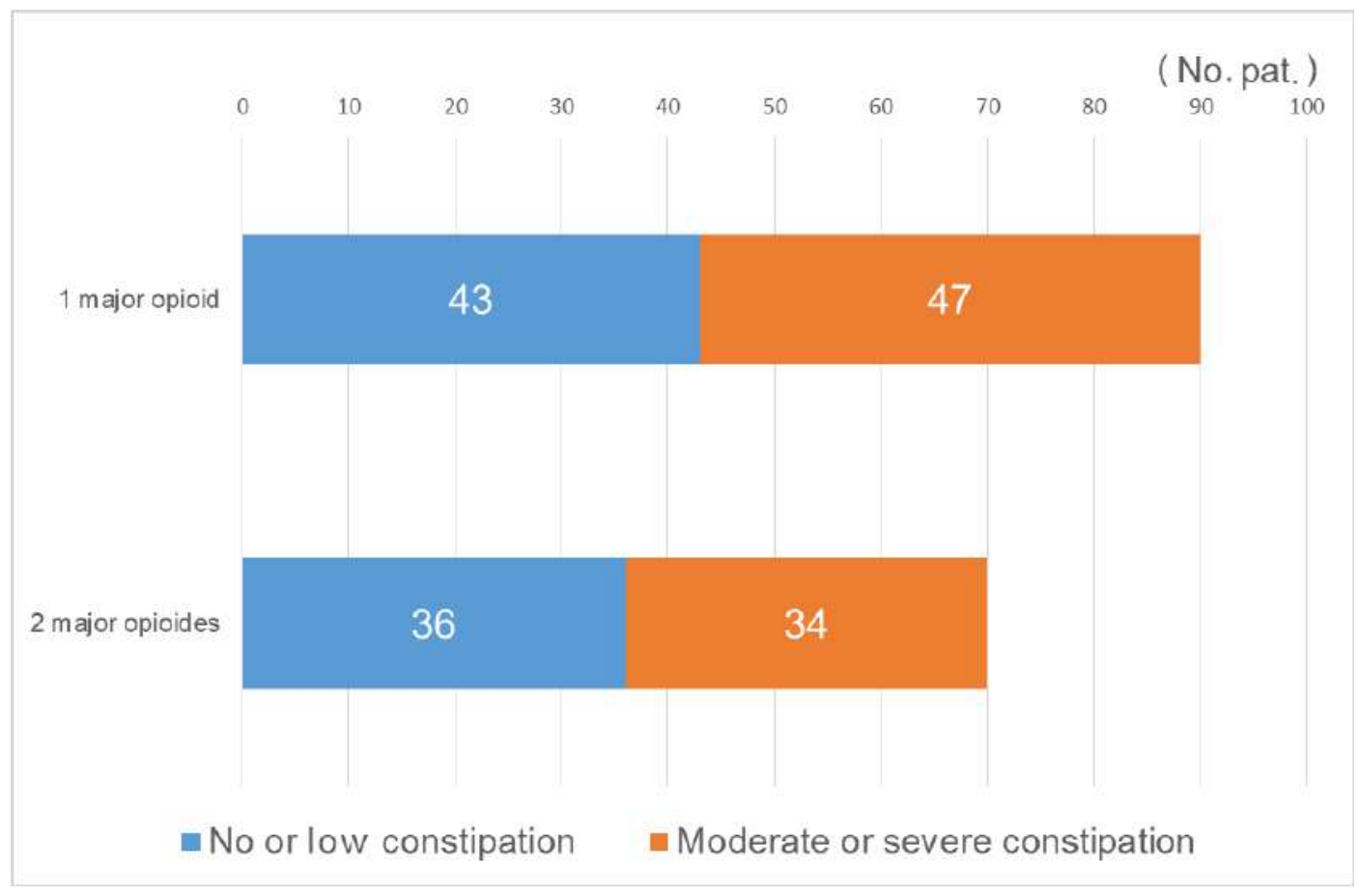

Figure 7. Distribution of patients according to the intensity of moderate constipation, after one week of treatment with lactulose. 


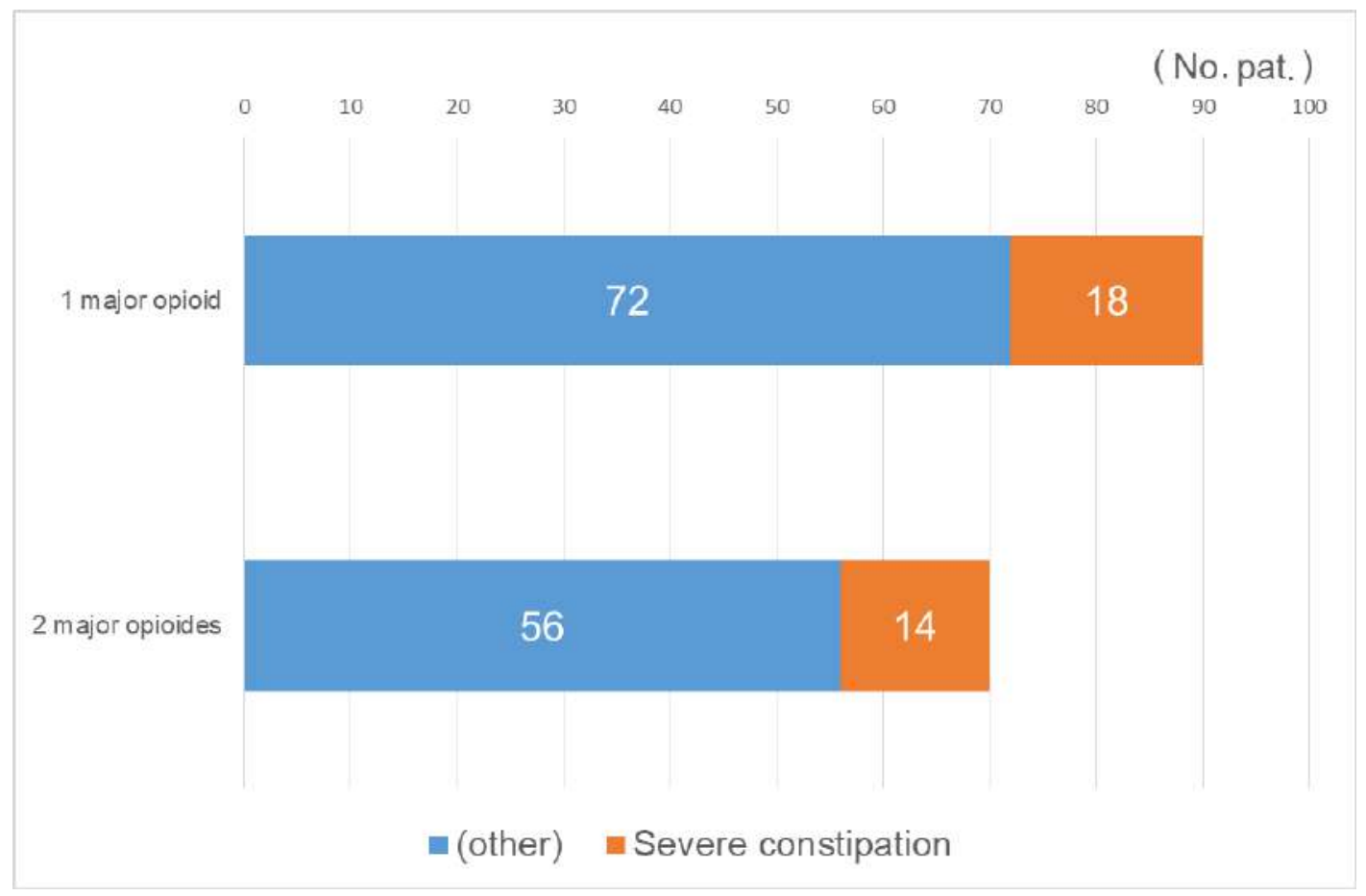

Figure 8. Distribution of patients according to the intensity of severe constipation, after one week of treatment with lactulose.

Three weeks after treatment initiation, under treatment with lactulose, among the patients with lowintensity constipation or no constipation at all and under treatment with lactulose and bisacodyl, and among the patients with moderate or high-intensity constipation, the distribution of patients according to the intensity of the constipation was: severe -16 patients, moderate 46 patients, low -74 patients, while 24 patients were not constipated at all. These results can be found in Figures 9, 10,11 .

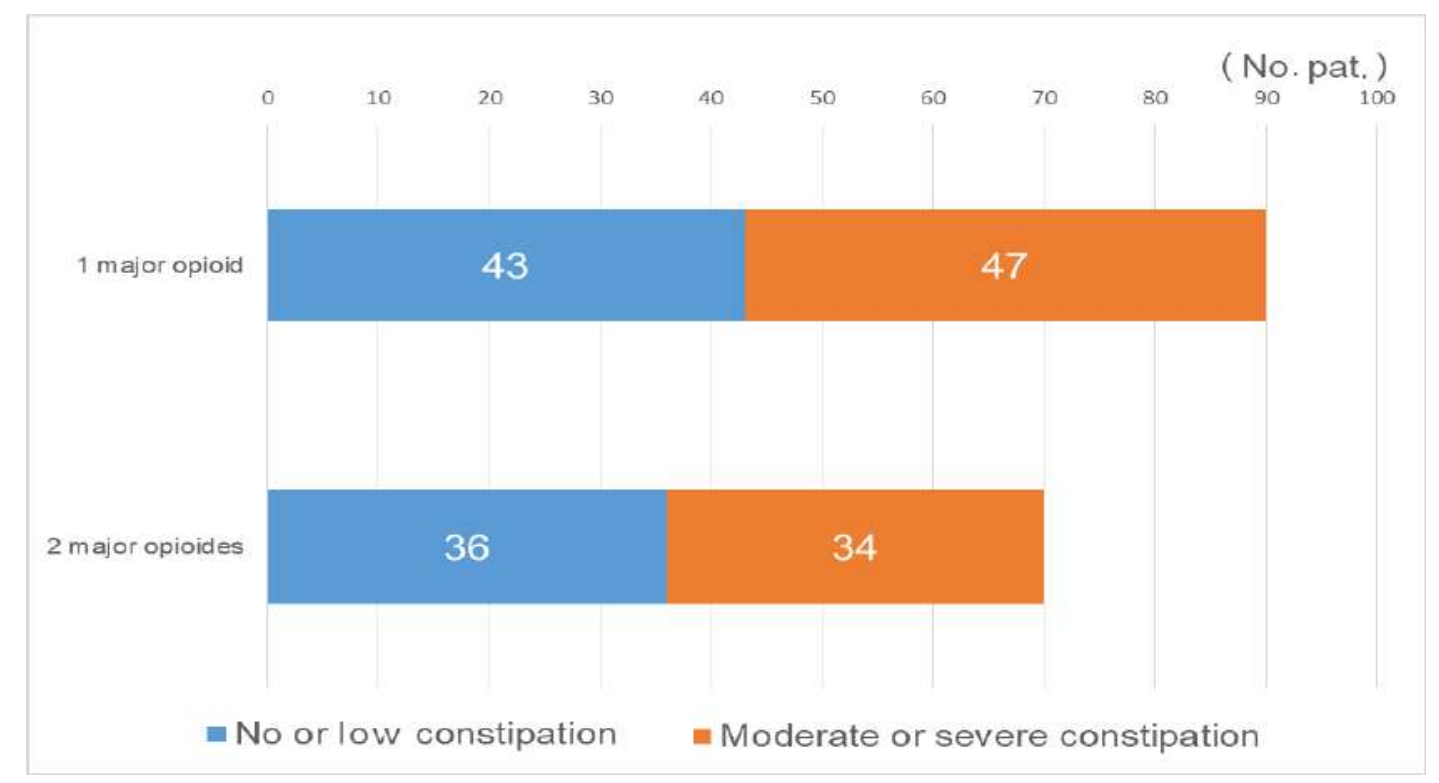

Figure 9. Distribution of patients according to the intensity of the constipation-moderate after 3 weeks of treatment with lactulose. 


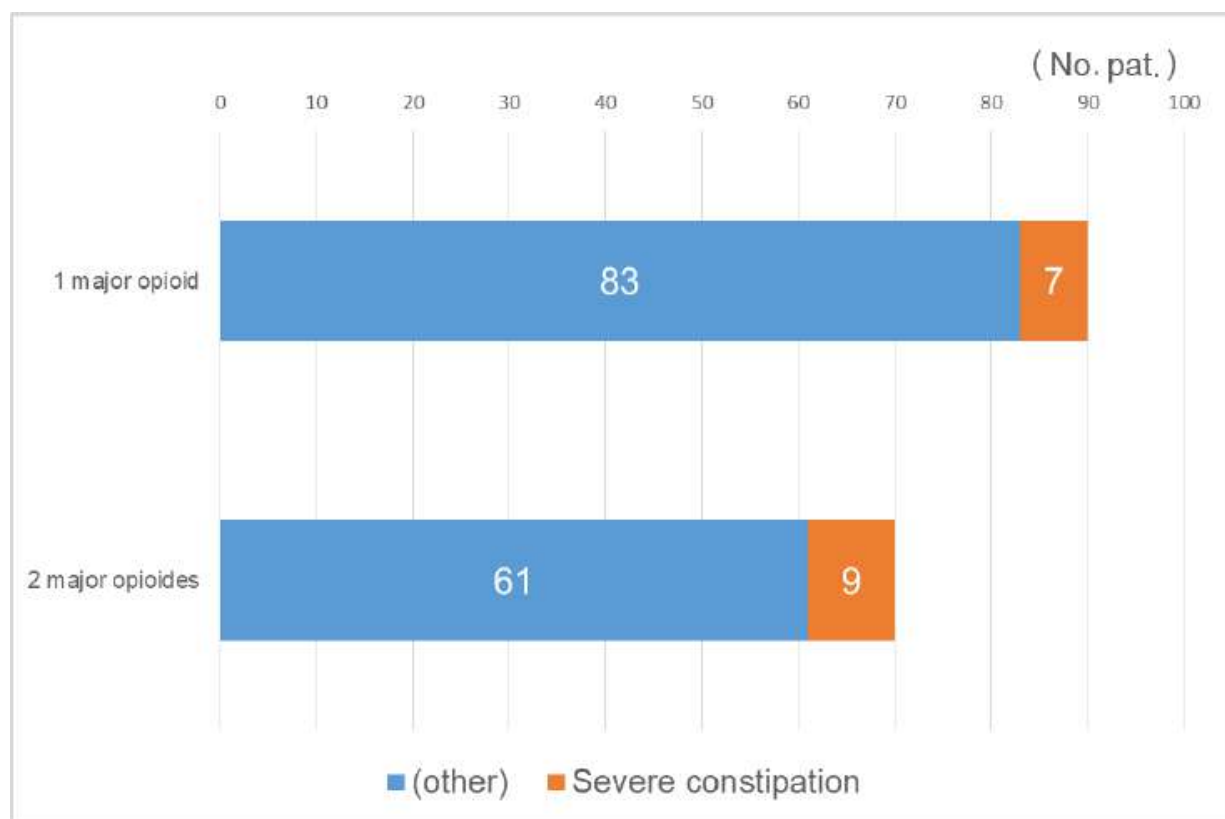

Figure 10. Distribution of patients according to the intensity of the constipation-moderate after 3 weeks of treatment with lactulose.

Micro-enemas were recommended to the 16 patients with high-intensity constipation after 3 weeks of treatment with 2 laxatives.

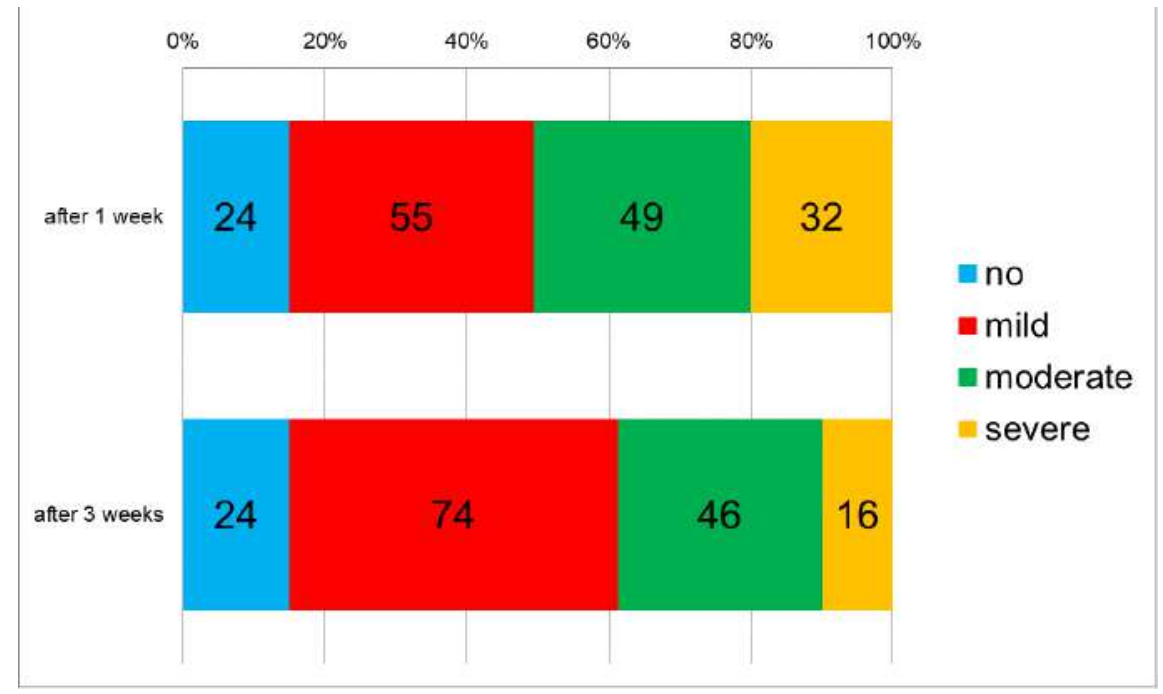

Figure 11. Assessment of constipation in all patients.

Patients in whom the intensity of constipation increased from low to moderate after 3 weeks of treatment with lactulose were also given bisacodyl, while in patients for whom the intensity of constipation decreased from moderate to low, under the association of two laxatives, the treatment was constant.

\section{Discussion}

According to WHO, strong opioids are indicated for moderate to severe pain, respectively for the $3^{\text {rd }}$ degree of pain, when analgesia is no longer achieved through low opioid treatment. Moreover, there are studies that have shown the efficacy of these drugs also in the treatment of dyspnea in patients with pulmonary neoplasia MAZILU $\&$ al [14] PARASCHIV \& al [15]. Opioids are subdivided into two classes, namely morphine and morphine-like substances. Morphine can be administered both parenterally (fast-release vials) and orally, under the form of tablets, respectively morphine sulphate (both fast-release and slow-release tablets) and hydrochloric morphine (slow-release tablets), morphine-like preparations are: 
oxycodone (fast-release and slow-release tablets), fentanyl (under the form of slow-release plasters or fast-release tablets), hydromorphone, and methadone PORTENOY [16].

Morphine is considered the gold standard in the treatment of neoplastic pain, but, there is no evidence to prove its superiority regarding the safety, the adverse effects or analgesia compared to other strong opioids. Therefore, the right choice for each patient cannot be foreseen, the relationship efficacy/safety/adverse reactions cannot be known before treatment initiation, and it is the clinician who will have to decide what medication of choice to elect first, based on his clinical experience and availability PORTENOY [17], BRATU \& al [18].

Patients should be warned from the beginning about the opioid treatment to acknowledge the potential adverse effects of these drugs. Since constipation has a strong psychological impact on patients, they should know about its risks of occurrence in order to prevent or, at least, to lower the risk of affecting the quality of life.

The therapeutic measures of constipation are both non-pharmacological and pharmacological. As to the approach from the lifestyle point of view, patients should be advised to have a good hydration, a fiber-rich diet and to do regular physical exercises VONDERHOLZER \& al [19]. Other non-pharmacological options are giving up opioid therapy, which is not desirable, or the rotation of opioids, which has also proven not efficient in improving the gastrointestinal adverse reactions LIU [20], MOCAN $\&$ al [21].

The ultimate and the most important approach is the pharmacological treatment of constipation. A wide variety of laxatives are used to treat constipation.

The guidelines of the European Association of Palliative Care (EAPC) recommend the administration of a laxative from the very beginning of the opioid treatment. Practically, this adverse reaction seems to be so common (in approximately $90 \%$ of the patients) that a preventive measure against constipation is required CARACENI \& al [22]. There is no evidence to support a clear answer regarding the efficacy of a laxative compared to another for cancer patients in case a question about the laxative of choice might be asked. Studies in the literature state, however, that the association of two laxatives with different mechanisms of action has proven more efficient than the administration of a single laxative, especially in case of constipation refractory to treatment LIU [19], MAZILU \& al [23]. The most common combination of laxatives is the association of a stimulant such as bisacodyl with a laxative which determines the increase of the fecal bolus, thus decreasing its consistency and determining intestinal lubrication, such as lactulose or sodium docusate MOCAN $\&$ al [20].

From the point of view of adverse reactions, laxatives are generally well-tolerated, but they can also cause nausea, vomiting, diarrhea, abdominal pain, a condition that requires the interruption of the treatment if it cannot be controlled CANDY \& al [24], CIUHU \& al [25]. Moreover, taking into account the fact that laxatives do not address the mechanism by which opioid-induced constipation occurs, sometimes, its control is impossible to achieve AMMEDZAI [26], YIPEL \& al [27], VAN DEN BEUREN $\&$ al [28], CIOCIRLAN \& al [29]. Therefore, it seems that strategies like opioid-antagonist therapy (methylnaltrexone, naloxone) could prove more efficient for such reasons, but they are not available nor used by clinicians as routine methods in all countries.

\section{Conclusions}

The prevalence of pain among cancer patients is very high, irrespective of the stage of the disease. Strong opioid therapy is the gold standard in the control of moderate to severe pain (3rd degree WHO). The oral administration is preferable, and there are a variety of substances, from morphine to similar preparations such as Oxycodone, Fentanyl, etc.

Constipation should be seriously taken into account and should be approached through preventive measures, which consist in changing the lifestyle through a richfiber diet, good hydration, regular physical exercises and pharmacological methods, such as the administration of a laxative or a combination of laxatives from the beginning of the analgesic treatment.

The most commonly used laxatives are those with osmotic action, such as mannitol/ lactulose, and the stimulant ones, such as bisacodyl.

\section{Acknowledgment}

All authors had equal contribution to this research.

\section{References}

1. X. LI, Y. DONG, H. LI, et al. Advances in the use of opioids in treating neuropathic cancer pain. Ann. Palliat. Med, 1:53-57 (2012).

2. A.M. TRESCOT.Review of the role of opioids in cancer pain. J. Natl. Compr. Canc. Netw, 8:10871094(2010).

3. S. DORN, A. LEMBO, F. CREMONINI. Opioidinduced bowel dysfunction: epidemiology, pathophysiology, diagnosis, and initial therapeutic approach. Am J Gastroenterol, 2:31-37 (2014).

4. P. HOLZER. Opioids and opioid receptors in the enteric nervous system: from a problem in opioid analgesia to a possible new prokinetic therapy in humans. Neurosci Lett, 361:192-195 (2004).

5. L. KUMAR, C. BARKER, A. EMMANUEL. Opioidinduced constipation: pathophysiology, clinical consequences, and management. Gastroenterol Res Prac, 2014:141737 (2014).

6. A. KURZ, D.I. SESSLER. Opioid-induced bowel dysfunction: pathophysiology and potential new therapies. Drugs, 63:649-671 (2003).

7. T.J. BELL, S.J. PANCHAL, C. MIASKOWAKI, et al. The prevalence, severity, and impact of opioidinduced bowel dysfunction: results of a US and 
European Patient Survey (PROBE 1). Pain Med 10:35-42 (2009).

8. S. HOLMES. Use of a modified symptom distress scale in assessment of the cancer patient. Int $J$ Nurs Stud, 26:69-79 (1989).

9. A. RUMMAN, R. G. ZANE, L. W. C. LIU. Opioid induced constipation in cancer patients: pathophysiology, diagnosis and treatment. Expert Review of Quality of Life in Cancer Care, 1(1):25-35 (2016).

10. M. TIGLIS, T.P. NEAGU T.P., M. ELFARA M., et al. Nefopam and its role in modulating acute and chronic pain. Rev Chim, 69(10):2877-2880 (2018).

11. I.M. BALMUS, A. CIOBICA, I. ANTIOCH, et al. Oxidative Stress Implications in the Affective Disorders: Main Biomarkers, Animal Models Relevance, Genetic Perspectives, and Antioxidant Approaches", Oxidative Medicine and Cellular Longevity, Article ID 3975101, 25 pages (2016).

12. E.C. DOBRICA, M.A. GAMAN, M.A. COZMA, et al. polypharmacy in type 2 diabetes mellitus: insights from an internal medicine department. Medicina, 55(8):, 436 (2019).

13. E. BRUERA, N. KUEHN, M.J. MILLER, P. SELMSER, K. MACMILLAN. The Edmonton Symptom Assessment System (ESAS): a simple method for the assessment of palliative care patients. J Palliat Care, 7(2):6-9(1991)

14. L. MAZILU, N. CIUFU, M. GALAN, A.I. SUCEVEANU, A.P. SUCEVEANU, I.R. PAREPA, D. TOFOLEAN. Posttherapeutic Follow-up of Colorectal Cancer Patients Treated with Curative Intent. Chirurgia, 107 (1): 55-58 (2012).

15. B. PARASCHIV, C.L. TOMA, C. DIACONU. Bronchiolo-alveolar carcinoma in a young patient: a case report. Archivos de Bronconeumologia, 49(7):315-316 (2013).

16. R.K. PORTENOY.Treatment of cancer pain Lancet. Crossref, Medline, 377: 2236-2247 (2011).

17. R.K. PORTENOY, A. EBTESAM. Principles of Opioid Use in Cancer Pain. Journal of Clinical Oncology, 32(16):1662-1670 (2014).

18. O.G. BRATU, A.I. CHERCIU, A. BUMBU, et al. Retroperitoneal tumors - treatment and prognosis of tumor recurrence. Rev Chim, 70(1):191-194 (2019).

19. W.A. VODERHOLZER, W. SCHATKE, B.E. MUHLDORFER, et al. Clinical response to dietary fiber treatment of chronic constipation. Am J Gastroenterol, 92:95-98 (1997).

20. L.W. LIU. Chronic constipation: current treatment options. Can J Gastroenterol,25 (Suppl B):22b-28b (2011).

21. A. MOCAN, L. VLASE, A.L. ARSENE, D. VODNAR, C. BISCHIN, R.S. DUMITRESCU, G. CRISAN. HPLC/MS analysis of caffeic and chlorogenic acids from three Romanian Veronica species and their antioxidant and antimicrobial properties. Farmacia, 63(6), 890-896 (2015).
22. A. CARACENI, G. HANKS, S. KAASA. et al. Use of opioid analgesics in the treatment of cancer pain: evidence-based recommendations from the EAPC. Lancet Oncol, 13:58-68 (2012).

23. L. MAZILU, Z. NICULESCU, A.I. SUCEVEANI, A.P. SUCEVEANU, D. TOFOLEAN, T. ADAM. Probleme de etică în comunicarea cu pacientul oncologic. Revista Română de Bioetică, 8(3): 81-87 (2010).

24. B. CANDY, L. JONES, M.L. GOODMAN, R. DRAKE, A. TOOKMAN. Laxatives or methylnaltrexone for the management of constipation in palliative care patients. Cochrane Database of Systematic Reviews, 1(Article ID CD003448) (2011).

25. A.N.CIUHU, A.M. PANTEA-STOIAN, C. NITIPIR, et al. Assessment of cachexia in cancer patients with advanced disease. Conference: $3^{\text {rd }}$ International Conference on Interdisciplinary Management of Diabetes Mellitus and its Complications (INTERDIAB) Location: Bucharest, ROMANIA Date: MAR 02-04, 2017 Sponsor(s): Assoc Renal Metab \& Nutrit Studies; Astra Zeneca Diabetes; MSD Diabetes; novo nordisk; SANOFI INTERDIAB 2017: DIABETES MELLITUS IN INTERNAL MEDICINE Book Series: International Conference on Interdisciplinary Management of Diabetes Mellitus and its Complications, 139-147 (2017).

26. S.H AHMEDZAI, F. NAUCK, G. BAR-SELA, B. BOSSE, P. LEYENDECKER, M. HOPPM. A randomized, double-blind, active-controlled, doubledummy, parallel-group study to determine the safety and efficacy of oxycodone/naloxone prolongedrelease tablets in patients with moderate/severe, chronic cancer pain, Palliative Medicine, 26(1):50-60 (2012).

27. M. YIPEL, M. GHICA, V. KAYA, M.G. ALBU, et al. Multifunctional Materials for Cancer Therapy: From Antitumoral Agents to Innovative Administration, Current Organic Chemistry, 20(28):2934-2948 (2016).

28. M.H.J. VAN DEN BEUKEN-VAN EVERDINGEN, J.M. DE RIJKE, A.G. KESSELES, H.C. SCHOUTEN, M. VAN KLEEF, J. PATIJN.Prevalence of pain in patients with cancer: a systematic review of the past 40 years. Annals of Oncology, 18(9):1437-1449 (2007).

29. M. CIOCIRLAN, L. DRAGHIA, D. MANUC et al. Nutritional status of patients with digestive cancers Conference: $3^{\text {rd }}$ International Conference on Interdisciplinary Management of Diabetes Mellitus and its Complications (INTERDIAB) Location: Bucharest, ROMANIA Date: MAR 02-04, 2017, Sponsor(s): Assoc Renal Metab \& Nutrit Studies; AstraZeneca Diabetes; MSD Diabetes; novo nordisk; SANOFI, INTERDIAB 2017: DIABETES MELLITUS IN INTERNAL MEDICINE Book Series: International Conference on Interdisciplinary Management of Diabetes Mellitus and its Complications, 132-138 (2017). 